\title{
Efficient Unstructured Grid Adaptation Methods for Sonic Boom Prediction
}

\author{
Richard L. Campbell ${ }^{1}$, Melissa B. Carter ${ }^{2}$, and Karen A. Deere ${ }^{3}$ \\ NASA Langley Research Center, Hampton, VA, 23606 \\ and \\ Kenrick A. Waithe ${ }^{4}$ \\ Gulfstream Aerospace Corporation, Savannah, GA, 31402
}

\begin{abstract}
This paper examines the use of two grid adaptation methods to improve the accuracy of the near-to-mid field pressure signature prediction of supersonic aircraft computed using the USM3D unstructured grid flow solver. The first method (ADV) is an interactive adaptation process that uses grid movement rather than enrichment to more accurately resolve the expansion and compression waves. The second method (SSGRID) uses an a priori adaptation approach to stretch and shear the original unstructured grid to align the grid with the pressure waves and reduce the cell count required to achieve an accurate signature prediction at a given distance from the vehicle. Both methods initially create negative volume cells that are repaired in a module in the ADV code. While both approaches provide significant improvements in the near field signature ( $<3$ body lengths) relative to a baseline grid without increasing the number of grid points, only the SSGRID approach allows the details of the signature to be accurately computed at mid-field distances (3-10 body lengths) for direct use with mid-field-to-ground boom propagation codes.
\end{abstract}

\section{Nomenclature}

$\begin{array}{ll}\Delta p / p & =\text { (local static pressure }- \text { free-stream static pressure }) / \text { free-stream static pressure } \\ H & =\text { vertical distance from body to boom measurement station } \\ L & =\text { reference length } \\ x & =\text { distance in the streamwise direction } \\ \text { Xcone } & =\text { distance in the streamwise direction relative to initial shock }\end{array}$

\section{Introduction}

$\mathrm{T}$ he prospect of supersonic flight for public and business transportation has spurred a significant amount of interest in recent years as reflected in both NASA and industry research programs. Early efforts such as the NASA Supersonic Transport research program and Concorde and Tu-144 development programs showed that, while commercial supersonic transportation was possible, it still had many obstacles to overcome before it could be economically and environmentally practical. After almost two decades of limited activity, interest in this flight regime was rekindled at NASA in the 1990's with the High-Speed Research Program, where numerous advances in areas such as structures, controls, propulsion and aerodynamics were made by the government and industry participants before the program ended in 1999. In particular, the application of computational fluid dynamics (CFD) was beginning to show promise for reliable analysis and design for improved vehicle cruise performance. ${ }^{1,2}$

One of the remaining hurdles for practical supersonic flight is the reduction of sonic boom over-pressures on the ground to levels that would allow supersonic flight over land. This issue was recently identified by the Super 10 consortium of aerospace companies as a key research objective for the development of a viable supersonic business jet. ${ }^{3}$ It should be noted, however, that supersonic flight over land is currently banned in most countries. As many companies feel that supersonic flight over land is necessary to the economics of a successful supersonic business jet,

\footnotetext{
${ }^{1}$ Senior Research Engineer, Configuration Aerodynamics Branch, MS 499, AIAA Associate Fellow.

2 Aerospace Engineer, Configuration Aerodynamics Branch, MS 499, AIAA Senior Member.

3 Aerospace Engineer, Configuration Aerodynamics Branch, MS 499, AIAA Senior Member.

${ }^{4}$ Applied Aerodynamics Technical Specialist, Preliminary Design, M/S R-01, PO Box 2206, AIAA Member.
}

1

American Institute of Aeronautics and Astronautics 
it is hoped that the current research into boom reduction will provide the technical foundation for a regulatory change.

The Supersonics Project in the NASA Fundamental Aeronautics Program reflects this priority in various research tasks for improving the prediction of sonic boom levels as well as ultimately designing for both reduced boom and drag. In similar recent efforts, NASA and DARPA have partnered with industry to conduct several joint research projects in which CFD was used in the design and evaluation of low-boom concepts. Two of these designs, the Shaped Sonic Boom Demonstrator ${ }^{4}$ and the Quiet Spike, ${ }^{5}$ were validated through flight tests; however, both addressed only the initial part of the aircraft shock system and involved relatively simple geometry changes near the front of the vehicle. As low-boom designs have proceeded to involve full aircraft configurations, details such as the integration of the propulsion system have become more important.

The prediction of sonic boom intensity is often accomplished by first obtaining a near-to-mid-field $(<10$ body lengths from aircraft) pressure distribution, either by measuring it in a wind tunnel or through the use of CFD. This mid-field pressure signature is then extended from a cruise altitude to ground level using propagation methods ${ }^{6}$ that include various atmospheric models. Unstructured CFD grids are somewhat easier to use than structured grids in modeling more complex geometries and can provide accurate surface and very near-field pressures $(<1.0$ body length); however, the distribution and orientation of the field grid has often been difficult to control and the resulting details as well as magnitudes of the pressure signature in the mid-field typically are not predicted with sufficient accuracy for use with the propagation codes.

This limitation is related to grid distribution and numerical dissipation in the flow solver. In-house studies indicate that isotropic refinement methods that add more points in the vicinity of shocks can produce better defined shocks in those regions, but do not necessarily allow the shocks to propagate accurately further into the flow field. This seems to imply that close grid spacing is required normal to the shocks and compression waves to adequately resolve the gradients, but a coarse grid spacing is needed in the propagation direction to minimize the number of cells traversed (and the resulting accumulated dissipation) to reach the mid-field. A number of different approaches have been tried to overcome this limitation. Several in-house studies indicated that grid enrichment codes can successfully produce finer details and sharper shocks, especially in close proximity to the vehicle, but often at the expense of much larger grids. Similar results were seen in the supersonic jet flow work of Pao. ${ }^{7}$ In addition, if the enrichment is non-directional, it can create more cells in the propagation direction, thus increasing the accumulated dissipation. Good results at larger distances have been obtained using error-driven adjoint-based grid adaptation, ${ }^{8,9}$ but the multiple runs required of both the flow and adjoint solvers can make the process cumbersome. A recent paper using a feature-based grid optimization method ${ }^{10}$ has shown promising results without the need for the adjoint information. Several authors ${ }^{11,12}$ have developed hybrid methods that use overset or unstructured grids to compute the very near-field solution, then use these results as boundary conditions for a structured grid case that will extend the pressures to mid-field. While this approach has also been successful, the complexity of setting up and interacting two different grids and flow solver runs would suggest that increasing the mid-field accuracy of the original unstructured grid solution and eliminating the need for a second grid would be a significant improvement to the process.

Toward this end, two grid adaptation methods have been developed and applied to several supersonic configurations. Both methods use grid movement rather than enrichment to improve grid spacing. This approach helps to minimize grid size, and since the original grid connectivity is maintained, allows restarts (if needed) without solution interpolation. A description of the adaptation methods as well as the flow solver used in their evaluation is included in the following section.

\section{Methods}

The following computational methods were used to generate the unstructured CFD grids used in this study, perform the flow analysis at supersonic test conditions, and modify the grids to obtain more accurate sonic boom signature predictions.

\section{A. TetrUSS Grid Generation and Flow Solver}

The TetrUSS CFD software package ${ }^{13}$ includes the VGRID grid generation code ${ }^{14}$ along with the USM3D Navier-Stokes flow solver. ${ }^{15}$ The VGRID code uses a combination of the advancing layers and advancing front methods to fill the computational domain with tetrahedral cells. The grid spacing is related to the strength of sources 
placed in the domain. While the original point and line sources can be used to control field grid density, the resulting grid is not very uniform. A newly developed source type, the volume source, ${ }^{16}$ allows much better control of field grid spacing and is discussed further in subsequent sections.

The USM3D code is a cell-centered, finite-volume Navier-Stokes flow solver that uses Roe flux-difference splitting ${ }^{17}$ to compute inviscid flux quantities across the faces of the tetrahedral cells. Several options for turbulent closure are available: the one-equation Spalart-Allmaras (S-A) model ${ }^{18}$ (with and without a wall function), and several two-equation models, including Menter's Shear Stress Transport (SST) model. ${ }^{19}$ The parallel version of the flow solver was run inviscidly using the implicit mode for the cases presented in this study. The minmod limiter was typically used to ensure numerical stability during the initial iterations, and was then turned off for the final cycles to minimize dissipation.

\section{B. ADV Interactive Adaptation Code}

The ADV adaptation code grew out of a grid movement method developed to modify an unstructured volume grid after surface design changes were made. The code initially determines what other points are connected to each grid point, then assigns the points to layers, starting with solid surface points as layer 1 . Any point that is connected to a layer 1 point and that has not been associated with a layer is assigned to layer 2, with this being repeated until all points assigned. For the grid movement code, the new location of each point was based on the movement of the nearest point in the previous layer, with constant perturbations through the boundary layer and decaying changes in the outer inviscid regions.

To provide a grid adaptation capability, a simple approach based on differences in distance and flow variable value between a point and its connected neighbors was implemented. The method has two modes of operation, one that tends to cluster points in regions of high gradient and a second that draws points into zones of high absolute value of the selected flow variable. The first mode has been used to improve the prediction of shear layers and shocks for jet flows ${ }^{7}$ as well as improve near-field shock signature in a hybrid unstructured/structured grid sonic boom prediction method. ${ }^{12}$ The second option has been used to provide better wake definitions for high-lift and aeroacoustic computations in in-house studies. A smoothing function can be invoked to balance the distances to the surrounding points and provide some control over cell aspect ratios.

During the grid movement process, some negative volume cells will typically be generated. The ADV code has several methods for fixing these cells. The primary technique involves moving the common face between a negative volume cell and the adjacent cell with the largest volume toward the larger cell. This approach is often all that is needed, but for more difficult cases, a second method that moves just one of the points in the bad cell based on the normal of the opposing face is also applied. In addition to cleaning up a grid after adaptation, the ADV code can provide a useful grid repair capability after other processes that involve grid movement, such as design or aeroelastic deformations.

While the ADV method is often used alone to provide a field grid adaptation capability, a companion code (AD) has also been developed to provide surface grid clustering using similar adaptation and smoothing algorithms. The points on component boundaries are automatically identified and their movement is restricted to the original boundary curves. The remaining surface points inside the boundaries are adjusted based on the ADV adaptation and smoothing algorithms, then projected back onto the component surface as defined by the original unstructured grid after each cycle. The grid can also be projected back to the underlying IGES definition periodically for greater accuracy in regions of high curvature. Currently, the surface adaptation is only implemented for use with pressure coefficient.

For viscous cases with surface adaptation, the flow is assumed to be attached so that the pressure is constant through the viscous layers of the grid. This implies that the movement of a grid point in the boundary layer will be the same as the movement of the corresponding surface point. If surface adaptation is not included, the field changes are reduced as the layer number approaches the surface for inviscid flows or the edge of the boundary layer for viscous cases. In the cases presented in this paper, only field adaptation is used.

\section{SSGRID a priori Adaptation Code}

Although interactive flow adaptation codes such as ADV can reduce the total number of grid points required to obtain a given level of accuracy, they can be somewhat cumbersome to use, even when the interaction between the flow solver and adaptation codes (including adjoint solver, if used) is automated. It is also typically true that they require more time than a fixed-grid analysis as each modification of the grid needs to be driven to a sufficient level of convergence to make the next adjustment with accuracy and stability.

An alternative approach to interactive grid adaptation is a priori adaptation, where the initial grid is clustered and oriented based on general flow characteristics that are known in advance of running the flow solver. Clustering 
surface grid points near the leading edge of a wing to resolve both the surface curvature as well as the flow acceleration is a common example of this knowledge-based approach used in both unstructured and structured grid generation. Control of the field grid characteristics is more difficult, especially for unstructured grids and even for structured grids around complex configurations. The VGRID unstructured grid generation code utilizes a variety of sources to provide some control of field grid placement. In particular, the recently-developed volume sources have been successfully used to control grid density and orientation in a number of applications. Although this approach can produce very good grids, it can be fairly user-intensive in the placement of the sources, and in the case of grids for sonic boom analysis, the process, including running the grid generation code itself, would have to be repeated for each new Mach number or angle of attack for a configuration.

The SSGRID a priori adaptation code avoids these drawbacks by modifying an original grid by shearing it to align the cells with the free-stream Mach angle and stretching it to reduce the number of points required to reach a given distance from the aircraft. The initial grid is typically generated using a relatively large field grid spacing except for a region of dense grid underneath the vehicle created using a vertical cylindrical volume source. As shearing the grid close to the body might cause it to intersect the wings or other components, an inner cylinder parallel to the body axis and just outside the wing tip is defined within which no grid modification occurs. This region tends to be much farther from the keel line of the aircraft than it needs to be and could allow unnecessary dissipation to occur before reaching the sheared grid. To remedy this, a variable inner cylinder radius is used based on the keel line. The keel line, primary inner cylinder radius and variable radius are all automatically determined in SSGRID based on the aircraft geometry and initial grid characteristics.

The grid points between the inner cylinder and outer boundary are first stretched in a radial direction to a userspecified distance, then sheared conically to match the free-stream Mach angle. This aligns the stretch direction with the shocks so that only a small flow gradient is encountered in that direction. As with the ADV code, the grid stretching and shearing in SSGRID will generally produce some negative volume cells, so the grid is run through ADV without adaptation to repair these cells. The entire process is automated and typically takes less than a minute to create a grid for each new Mach number/angle-of-attack combination.

\section{Results}

A number of configurations have been analyzed using ADV and/or SSGRID at supersonic cruise conditions. Grid sizes ranged from about 3 to 11 million cells, depending on the complexity of the configuration and shock pattern. Sample results for several of the configurations, compared with wind tunnel or flight data when available, are shown below. The boom signatures are shown as the difference of the local and free-stream static pressures divided by the free-stream pressure $(\Delta \mathrm{p} / \mathrm{p})$ versus the streamwise location $(\mathrm{x})$ for different distances below the vehicle nondimensionalized by a reference body length $(\mathrm{H} / \mathrm{L})$.

\section{A. CLE}

The CLE (Continuous Leading Edge) model is a NASA in-house wing-body configuration designed to have a weak sonic boom signature. The surface grid for the wind tunnel model with an integrated sting is shown in figure 1. Also seen in the figure is the grid for the symmetry plane as modified by ADV at the cruise Mach number of 2.0 and angle of attack of 2.5 degrees. The clustering of the grid to better resolve the expansion and compression waves is obvious and the change in boom signature relative to the baseline grid can be seen as a function of adaptation cycle number in figure 2. At this station, which is fairly close to the model $(\mathrm{H} / \mathrm{L}=0.65)$, the predicted initial shock peak has increased by about 50\% in 3-5 cycles. Figure 3 shows a comparison of the ADV results after 3 adaptation cycles with wind tunnel data at 3 different distances from the model. While the correlation is reasonably good at $\mathrm{H} / \mathrm{L}=1.0$, the ADV results lack detail and do not match the peak values at the more distant stations. Referring to figure 1, it can be seen that the grid is coarse away from the body and the points tend to cluster around the stronger features, thus "starving" the weaker shocks. This case would probably benefit from a volume source approach which can decrease the axial spacing independent of the vertical spacing.

The SSGRID method was also applied to the CLE configuration with the outer boundary stretched to about seven body lengths from the model. The results, shown in figure 4, indicate that SSGRID produces much better agreement with the experimental data than was seen with ADV. While this grid was somewhat coarse (about 6 million cells) and did not use the volume source approach, significant detail was retained even to $H / L=3.0$ and the shock magnitudes were matched fairly well. The discrepancy between theory and experiment for the aft expansion is being investigated and appears to be due to an inconsistency in the geometry definition of the sting/fuselage intersection. 


\section{B. WBVS}

The WBVS (Wing/Body/Vertical-tail/Spike) configuration shown in figure 5 was supplied to NASA by Gulfstream as part of a cooperative program for basic research in CFD design methods and wind tunnel testing techniques for low-boom, low-drag supersonic aircraft. The nose spike is a concept proposed and developed by Gulfstream for tailoring the boom signature of an aircraft. ${ }^{5}$ For this configuration, the volume source approach was used to provide a dense region of grid underneath the aircraft (see figure 6) to help resolve the weak, closely-spaced waves coming from the spike. The grid spacing for this initial analysis is finer than needed in the rest of the field, resulting in a grid of about 11 million cells.

The symmetry plane grid close to the body is shown in figure 7 for four cases: baseline (dorig), ADV (dad5), SSGRID with shearing and stretching that moved the outer boundary out one additional body length (ds1), and SSGRID with shearing and stretching that moved the outer boundary out ten body lengths (ds10). Thus, for the baseline and ADV cases, the outer boundary is a cylinder with a radius of one body length $(\mathrm{H} / \mathrm{L}=1.0)$ and for the SSGRID ds 1 and ds10 cases, the outer boundary has been stretched to approximately $\mathrm{H} / \mathrm{L}=2$ and $\mathrm{H} / \mathrm{L}=11$, respectively. Results at the cruise Mach number of 1.6 and angle of attack of 0.0 for the first three cases are plotted in figure 8 , with the scales adjusted to a smaller range as the distance from the model increases to highlight differences in pressure level. Comparing the ADV and baseline signatures, the adaptation provides a noticeable improvement in peak heights for the spike signature at $\mathrm{H} / \mathrm{L}=0.25$. Note that this is the approximate location for the beginning of the intermediate structured grid for the hybrid method of reference 11, where ADV was also reported to have provided some benefit. $\mathrm{By} \mathrm{H} / \mathrm{L}=0.5$, the details of the spike signature are beginning to wash out, though some improvement in the aft features is still present, even at $\mathrm{H} / \mathrm{L}=1.0$, which is on the far-field boundary where the grid is unchanged from the baseline. For the ds 1 case, the outer boundary has been pushed out to about $\mathrm{H} / \mathrm{L}=2$, so while there is some cell stretching, the main effect should be the shearing of the grid. As can be seen, much more detail and peak strength is retained at all three of the stations.

Figure 9 compares the ds 1 and ds 10 cases at these inner stations to show the impact of stretching the sheared grid. The two SSGRID signatures are similar, with the primary differences between them at the inner two stations being a reduction in peak strength for the initial weak shock and a stronger aft compression for the ds 1 results. The initial peak as well as the other spike peaks remain stronger at $\mathrm{H} / \mathrm{L}=1.0$ for the ds 10 case, suggesting that stretching does indeed help the signal to propagate with less dissipation. The aft compression discrepancy is not present at this station, indicating perhaps a problem with the data extraction at the inner stations.

Since the ds 10 case outer boundary was extended beyond 10 body lengths from the model, additional cuts were made to examine the propagation of the boom signature into the mid-field. Figure 10 shows that significant detail is retained to $\mathrm{H} / \mathrm{L}=10$ with features of the weak spike shocks still evident at $\mathrm{H} / \mathrm{L}=6$. The SSGRID approach with higher stretching appears to be very effective, while noting that regions of weak shocks (such as the spike) may require a denser initial grid. Wind tunnel tests of a related configuration are part of the NASA Supersonics Project in the Fundamental Aeronautics Program and should provide data for further validation of this approach.

While improvements to the ADV results could probably be obtained by using a better initial grid or modifying the adaptation/smoothing algorithms, it is evident that SSGRID is a simpler, more effective approach at this time. Some attempts have also been made to combine the two methods by applying ADV after running SSGRID. While some minor improvements were achieved in the steepness and peak levels of shocks and expansions, the changes were small and probably did not justify the additional effort. The following cases use only SSGRID and include experimental data at mid-field distances.

\section{Cone}

An unstructured grid having 8.6 million cells was developed for the 6.48 degree cone model 1a in reference 20 . The initial grid had a rectangular outer boundary grid that extended one body (cone) length ahead of, above, below and to the side of the nose and three body lengths downstream of the end of the cone. A cylindrical volume source was placed just under the model and extended to the lower outer boundary, with a diameter that extended 0.2 body lengths ahead of and behind the cone. The cell size parameters for the volume source were 0.005 and 0.01 body lengths in the radial direction at the top and bottom of the source, respectively. The sizes in the direction of the cylinder axis were twice the corresponding radial values, providing some initial grid stretching before the application of SSGRID. The initial surface grid for the cone/sting and the symmetry plane grid are shown in figure 11. The grid was then stretched to put the lower edge of the symmetry plane at slightly more than 10 body lengths below the nose and sheared back at the Mach angle corresponding to the test Mach number of 1.68. This grid was run in USM3D with the minmod limiter on and off and the resulting pressures on the symmetry plane at 10 body lengths below the model are compared with wind tunnel data in figure 12. The agreement is very good overall, with 
the limiter-off case (solid blue line) matching the aft expansion better but giving a very slight overshoot of the peak compression at $\mathrm{x} / \mathrm{L}$ of 0.9 .

\section{Delta Wing}

The delta wing configuration (model 4) of reference 21 was selected to provide a more complex boom signature for evaluating SSGRID. The extent of the outer boundary and volume source placement and sizing were similar to the cone case (see figure 13), resulting in a grid size of 10.3 million cells. As the data location in this case was only 3.6 body lengths below the model, a stretching factor of 5 was used along with M=1.68 as input to SSGRID. The resulting centerline pressure signature is shown in figure 14. As with the cone, the overall agreement with the wind tunnel data is very good, with a discrepancy in the aft signature that is related to inaccuracies in modeling the model/sting juncture. For this case, turning off the limiter did not significantly change the results.

\section{E. F-15QS}

An even more challenging configuration is the F-15QS (Quiet Spike) configuration. This aircraft was used in a basic research flight test program ${ }^{5}$ run by NASA in cooperation with Gulfstream to evaluate an extendable nose spike similar to the one on the WBVS configuration above (see figures 5 and 15). The flow-field emanating from the F-15QS aircraft was probed at various distances and radial angles by a second aircraft to provide boom signatures in the near- and mid-field regions. Included in these signatures were strong shocks from the basic aircraft as well as the weak shocks from the spike that were the focus of the research.

For this configuration, a very coarse outer initial grid was used with denser grid underneath the aircraft specified using volume sources. Based on the results for the WBVS case, a second volume source with smaller radial spacing was placed below the spike as shown in figure 16. The symmetry planes for the final and stretched grids are shown in figures $17 \mathrm{a}$ and $17 \mathrm{~b}$, with close-up views in the region of the spike shown in $17 \mathrm{c}$ and $17 \mathrm{~d}$. The final grid had about 9 million cells. Figure 17d shows how the variable inner cylinder radius in SSGRID allows the grid modifications to begin very close to the body and thus minimize the dissipation as the waves are propagated to the mid-field.

Figure 18 shows a comparison between the SSGRID results and flight data at four distances directly below the aircraft at a Mach number of 1.4 and angle of attack of 1.8 degrees. For these plots, the streamwise location, $\mathrm{x}_{\text {cone, }}$, is the distance behind a theoretical bow-shock. The correlation is very good in general, with some discrepancies in the aft part of the signature attributable at least in part to differences in the CFD and flight geometries noted in reference 12. Especially encouraging was the accurate prediction of the spike shocks at the outer two stations, with only a slight decay of the initial peak at the last station. To put this result in context with results from other grid adaptation methods, it is noted that the spike geometry is similar to the double cone-cylinder geometry shown in references 8 10. By way of comparison, the outer two stations shown in figures $18 \mathrm{c}$ and $18 \mathrm{~d}$ are at the equivalent of 46 and 69 double cone-cylinder body lengths based on initial cylinder diameter, whereas the most distant data available for comparison with the double cone-cylinder case was at 20 body lengths.

\section{Concluding Remarks}

While both the ADV and SSGRID grid adaptation methods provided improved calculations of boom signature in the near field relative to a baseline grid, the SSGRID approach was by far the easier to use, provided more detail in the near-field, and retained the detail into the mid-field. The shearing of the grid to align the faces with the Mach angle provided most of the improvement relative to the original grid, but the grid stretching was also important in allowing the signature to propagate to the midfield with minimal dissipation. The use of the new volume sources in VGRID greatly simplified the creation of the dense grid region under the aircraft and kept the overall grid size reasonable. It would appear that the accuracy of the SSGRID approach is at least comparable to other published adaptation and hybrid grid approaches with perhaps an advantage in ease of use and improved run time. The ability to quickly develop new grids for different Mach numbers and angles of attack is also a very useful feature of SSGRID. 


\section{References}

1Agrawal, Shreekant; and Narducci, Robert: "Drag Prediction using Nonlinear Computational Methods", AIAA-2000-0382, January 2000.

${ }^{2}$ Cliff, Susan E.; Reuther, James J.; Saunders, David A.; and Hicks, Raymond, M.: "Single-Point and Multipoint Aerodynamic Shape Optimization of High-Speed Civil Transport", Journal of Aircraft, Vol.38, No. 6, Novenmber-December 2001, pp.997-1005.

"Lowering the Boom", The X-Press, NASA Dryden Flight Research Center, Volume 47, Issue 4, July 29, 2005, URL: http://www.nasa.gov/centers/dryden/news/X-Press/stories/2005/072905 LoweringTheBoom.html .

${ }^{4}$ Pawlowski, Joseph W.; Graham, David H.; Boccadoro, Charles H.; Coen, Peter G.; and Maglieri, Domenic J.: "Origins and Overview of the Shaped Sonic Boom Demonstration Program”, AIAA-2005-5, January 2005.

${ }^{5}$ Howe, Donald C.; Waithe, Kenrick A.; and Haering, Edward A., Jr.: "Quiet Spike ${ }^{\mathrm{TM}}$ Near Field Flight Test Pressure Measurements with Computational Fluid Dynamics Comparisons”, AIAA-2008-128, January 2008.

${ }^{6}$ Plotkin, Kenneth K.; and Page, Juliet A.: "Extrapolation of Sonic Boom Signatures from CFD Solutions", AIAA-20020922, January 2002.

${ }^{7}$ Pao, S. Paul.; Abdol-Hamid, Khaled S.; Campbell, Richard L.; Hunter, Craig A.; Massey, Steven J.; and Elmiligui, Alaa A.: "Unstructured CFD and Noise Prediction Methods for Propulsion Airframe Aeroacoustics", AIAA-2006-2597, May 2006.

${ }^{8}$ Jones, W.T.; Nielsen, E.J.; and Park, M.A.: "Validation of 3D Adjoint Based Error Estimation and Mesh Adaptation for Sonic Boom Prediction", AIAA-2006-1150, January 2006.

${ }^{9}$ Park, Michael A.; and Darmofal, David L.: "Output-Adaptive Tetrahedral Cut-Cell Validation for Sonic Boom Prediction", AIAA-2008-6594, August 2008.

${ }^{10}$ Ozcer, Isik A.: and Kandil, Osama A.: "FUN3D / OptiGRID Coupling for Unstructured Grid Adaptation for Sonic Boom Problems", AIAA-2008-61, January 2008.

${ }^{11}$ Laflin, Kelly R.; Klausmeyer, Steven M.; and Chaffin, Mark: “A Hybrid Computational Fluid Dynamics Procedure for Sonic Boom Prediction”, AIAA-2006-3168, June 2006.

${ }^{12}$ Waithe, Kenrick A.: “Application of USM3D for Sonic Boom Prediction by Utilizing a Hybrid Procedure", AIAA-2008129, January 2008.

${ }^{13}$ Frink, N.T., Pirzadeh, S.Z., Parikh, P.C., Pandya, M.J., and Bhat, M.K.: "The NASA Tetrahedral Unstructured Software System", The Aeronautical Journal, Vol. 104, No. 1040, October 2000, pp.491-499.

${ }^{14}$ Pirzadeh, S.: "Three-Dimensional Unstructured Viscous Grids by the Advancing-Layers Method", AIAA Journal, Vol. 34, No. 1, January 1996, pp.43-49.

${ }^{15}$ Frink, N.T.: “Assessment of an Unstructured-Grid Method for Predicting 3-D Turbulent Viscous Flows", AIAA-96-0292, January 1996.

${ }^{16}$ Pirzadeh, Shahyar, Z.: “Advanced Unstructured Grid Generation for Complex Aerodynamics Applications”, AIAA-20087178, August 2008.

${ }^{17}$ Roe, P.: "Characteristic Based Schemes for the Euler Equations", Annual Review of Fluid Mechanics, Vol. 18, 1986, pp. 337-365.

${ }^{18}$ Spalart, P.; and Allmaras, S.A.: “One-Equation Turbulence Model for Aerodynamic Flows”, AIAA 92-0439, January 1992.

${ }^{19}$ Menter, F.R.: "Improved Two-Equation k-omega Turbulence Models for Aerodynamic Flows”, NASA TM-103975, October 1992.

${ }^{20}$ Mendoza, Joel P.; and Hicks, Raymond M.: "Further Studies of the Extrapolation of Near-Field Overpressure Data", NASA TM X-2219, March 1971.

${ }^{21}$ Hunton, Lynn W.; Hicks, Raymond M.; and Mendoza, Joel P.: "Some Effects of Wing Planform on Sonic Boom", NASA TN D-7160, January 1973. 


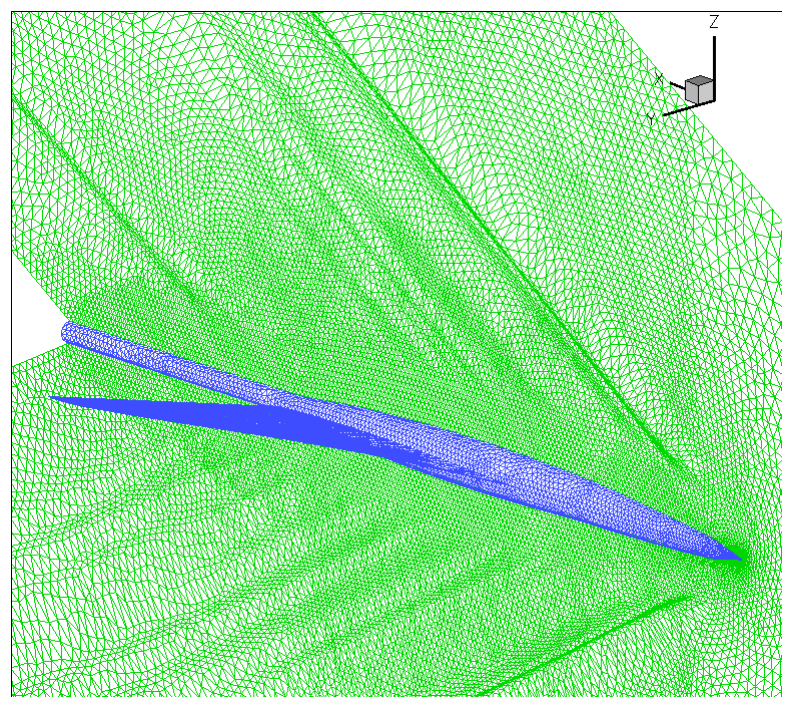

Figure 1 - CLE grid.

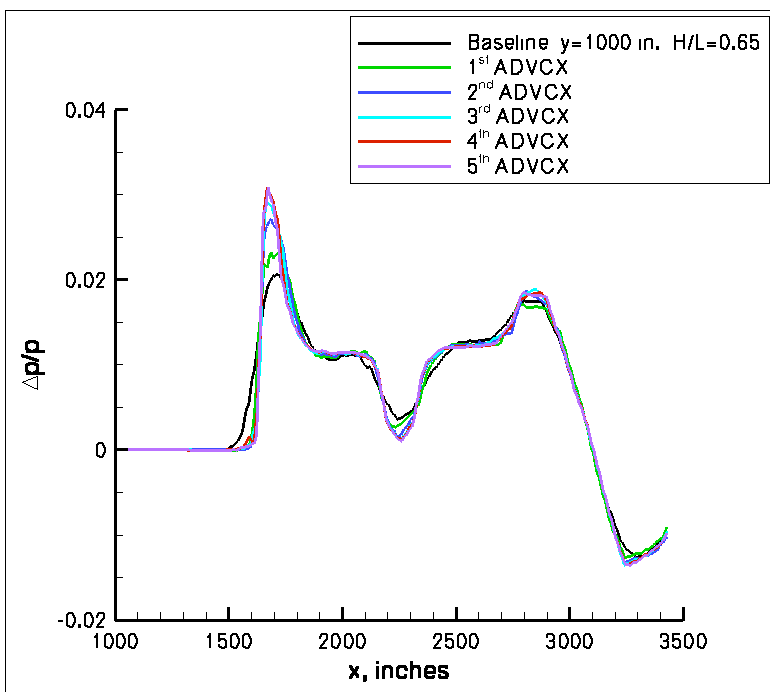

Figure 2 - Effect of ADV on near-field signature.

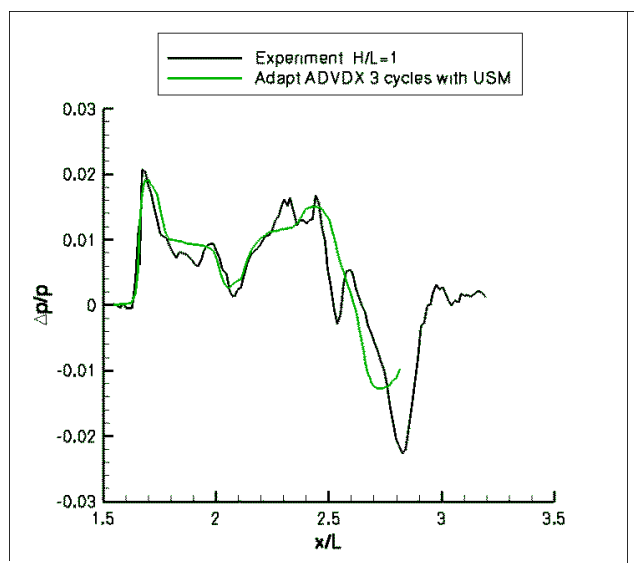

a) $\mathrm{H} / \mathrm{L}=1$

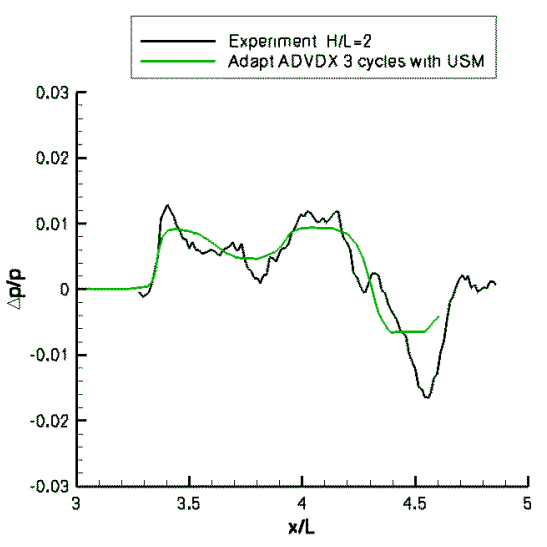

b) $\mathrm{H} / \mathrm{L}=2$

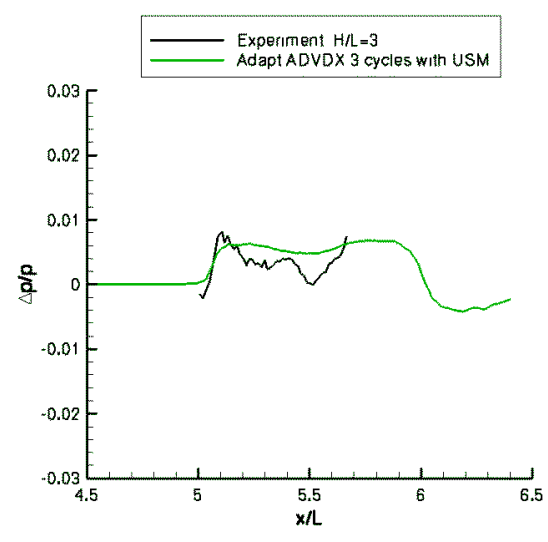

c) $\mathrm{H} / \mathrm{L}=3$

Figure 3 - Comparison of ADV results with wind tunnel data for CLE.

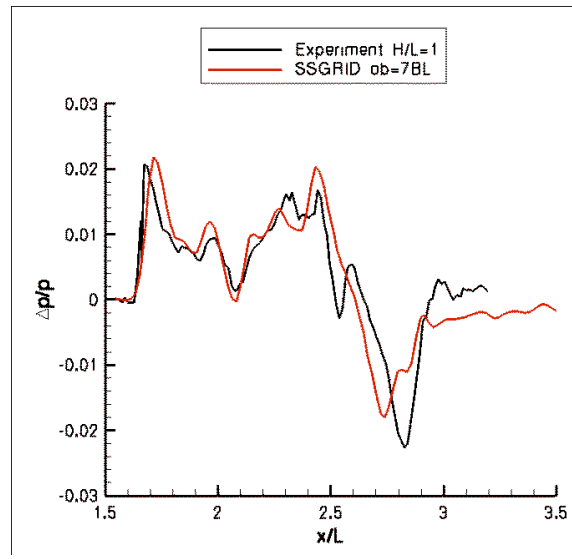

a) $\mathrm{H} / \mathrm{L}=1$

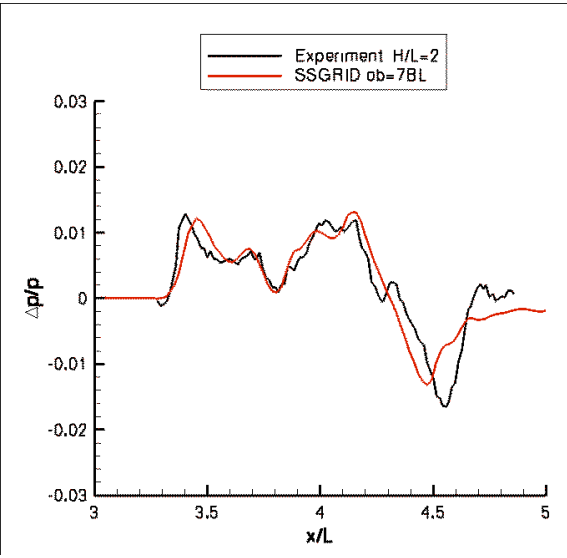

b) $\mathrm{H} / \mathrm{L}=2$

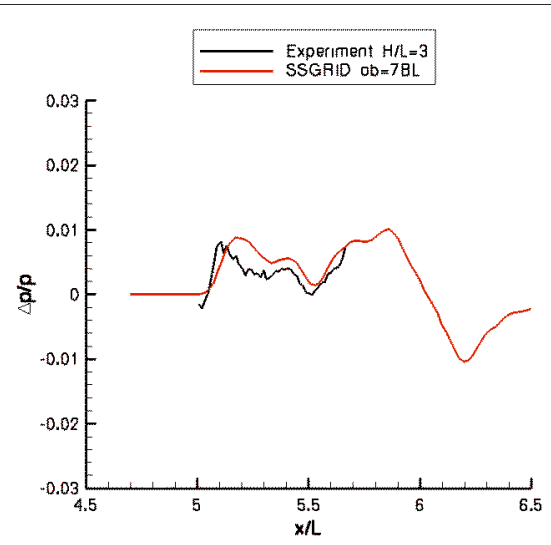

c) $\mathrm{H} / \mathrm{L}=3$

Figure 4 - Comparison of SSGRID results with wind tunnel data for CLE. 


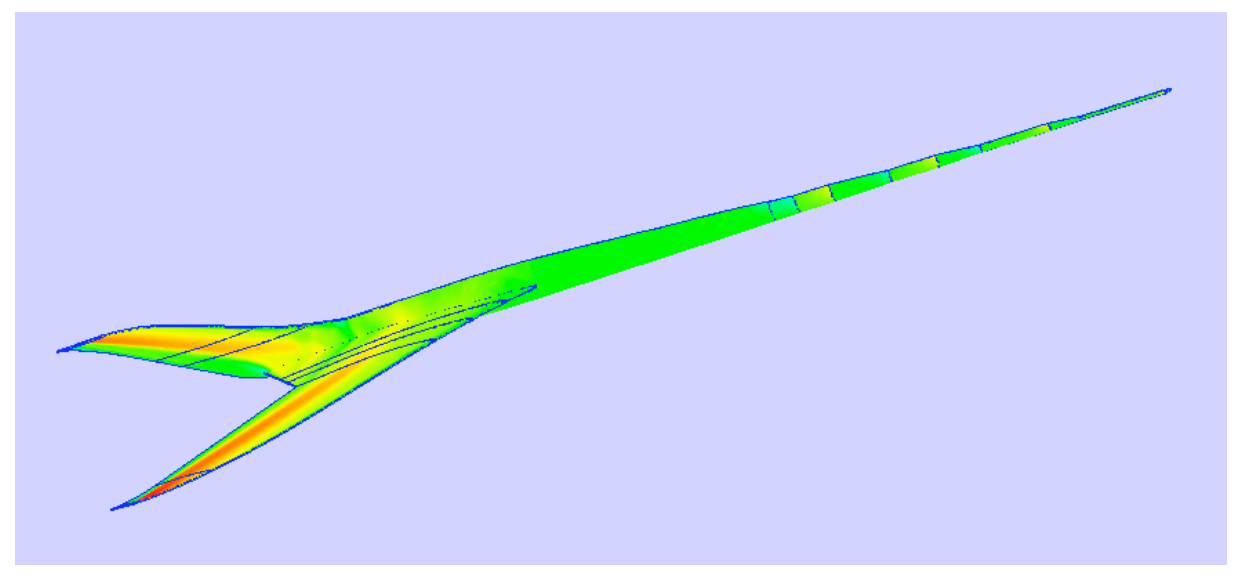

Figure 5 - WBVS configuration

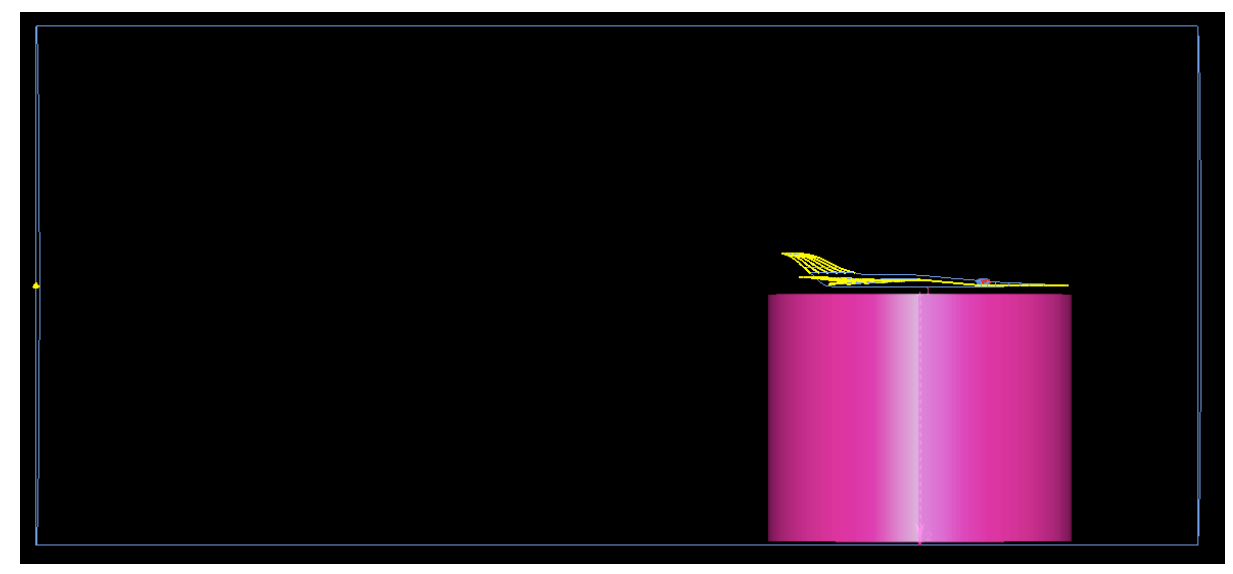

a) Volume source location

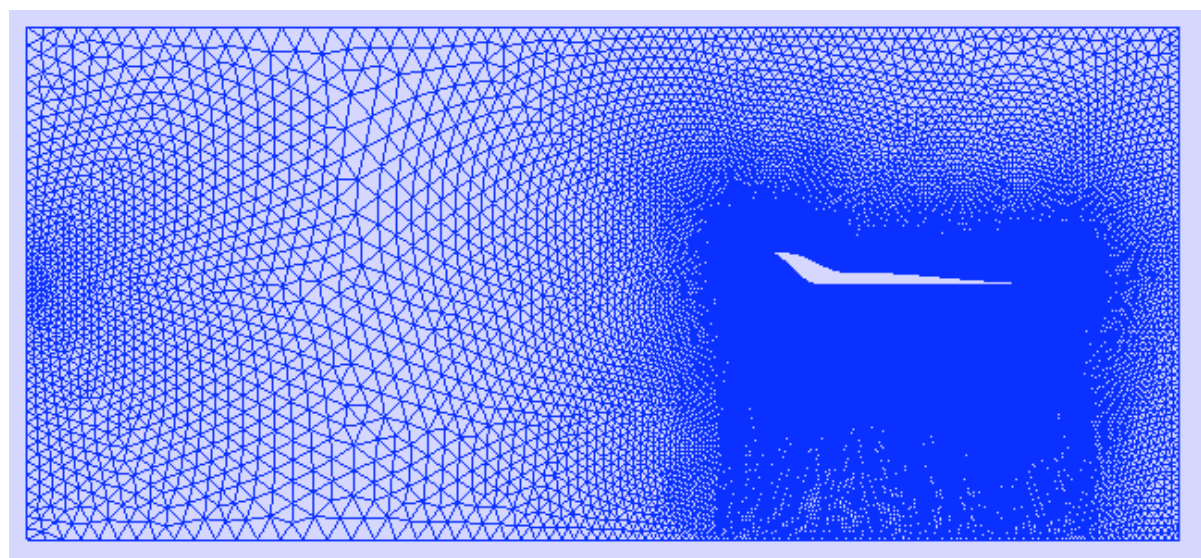

b) Symmetry plane grid

Figure 6 - Location of volume source and resulting grid for WBVS. 


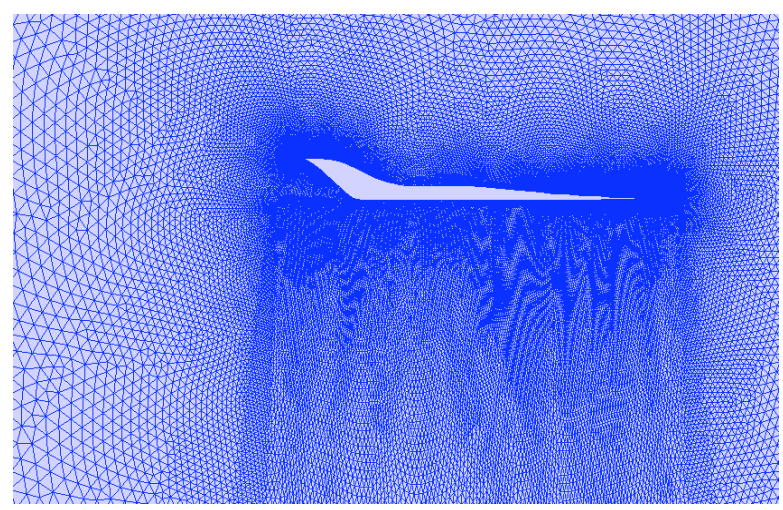

a) Baseline grid (dorig)

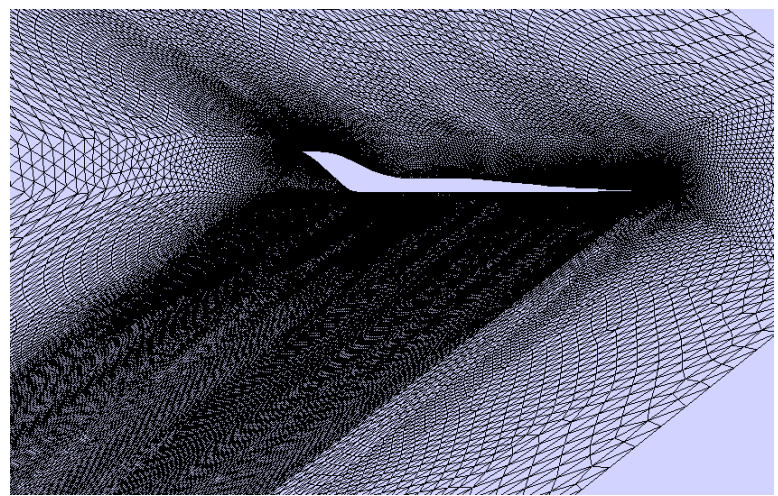

c) SSGRID low stretching (ds1)

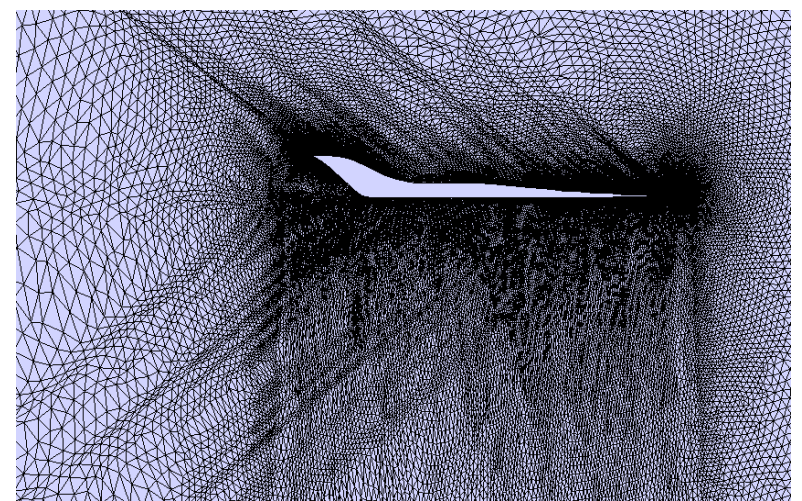

b) ADV grid (dad5)

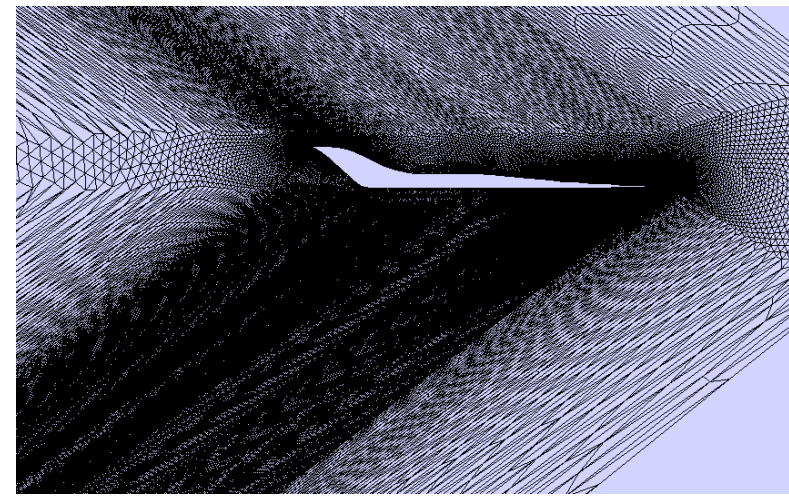

d) SSGRID high stretching (ds10)

Figure 7 - Symmetry plane grids for WBVS cases. 


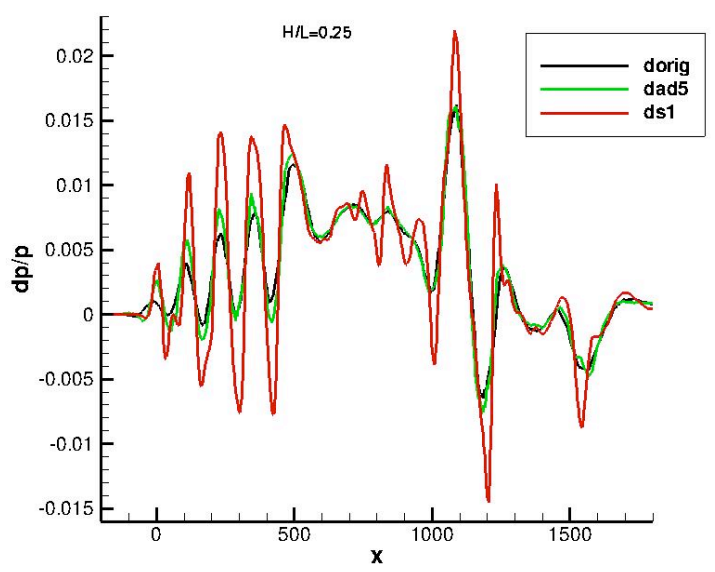

a) $\mathrm{H} / \mathrm{L}=0.25$

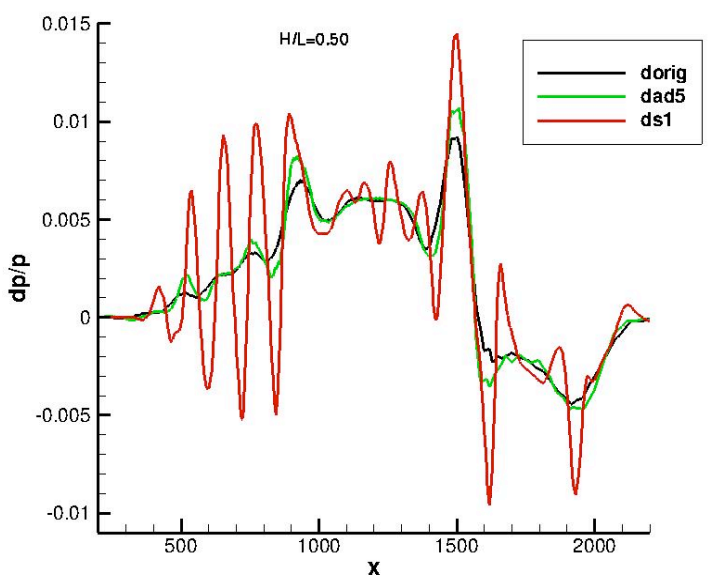

b) $\mathrm{H} / \mathrm{L}=0.50$

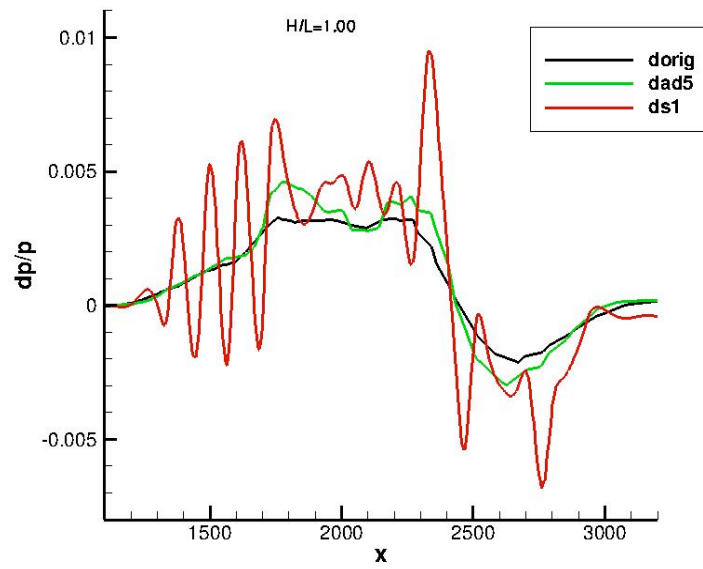

c) $\mathrm{H} / \mathrm{L}=1.00$

Figure 8 - Near-field signatures for baseline, ADV and SSGRID low stretching cases.

11

American Institute of Aeronautics and Astronautics 


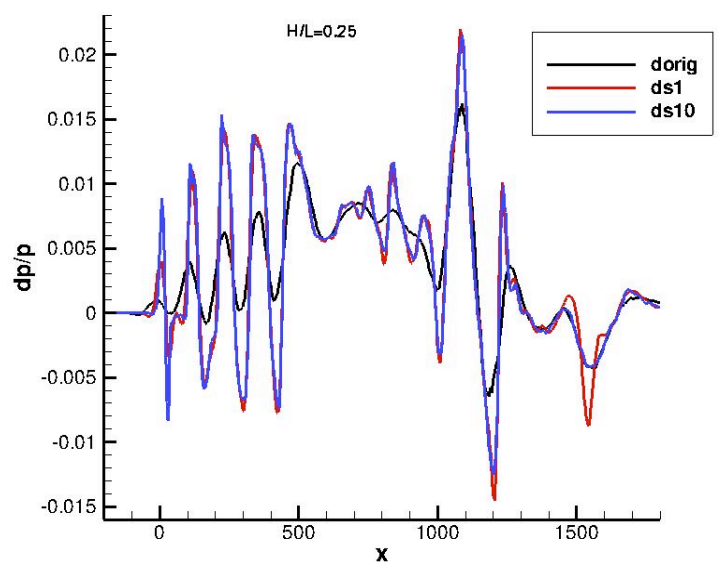

a) $\mathrm{H} / \mathrm{L}=0.25$

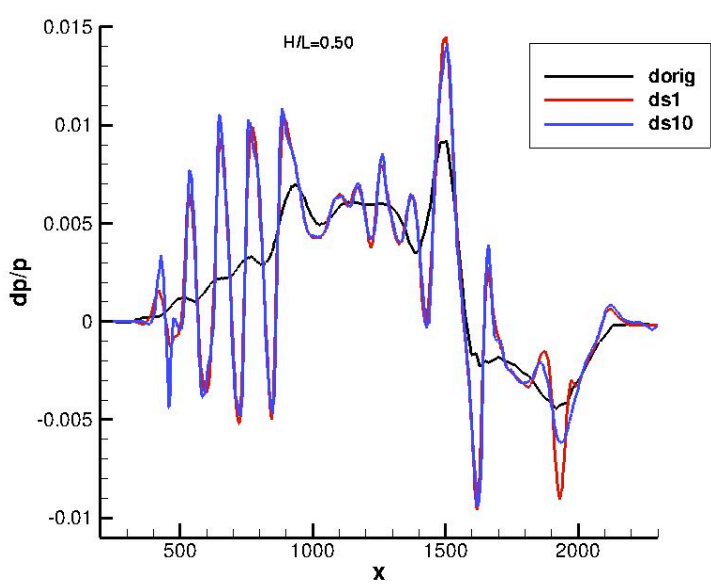

b) $\mathrm{H} / \mathrm{L}=0.50$

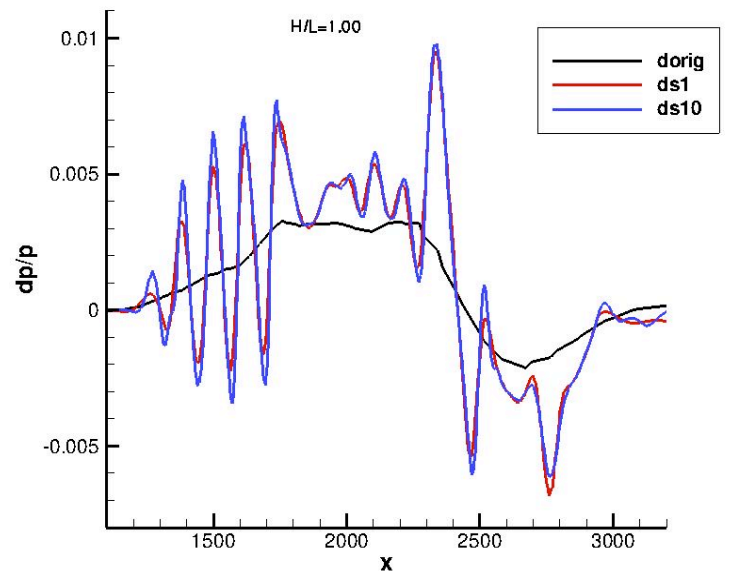

c) $\mathrm{H} / \mathrm{L}=1.00$

Figure 9 - Effects of level of stretching in SSGRID on near-field signatures. 


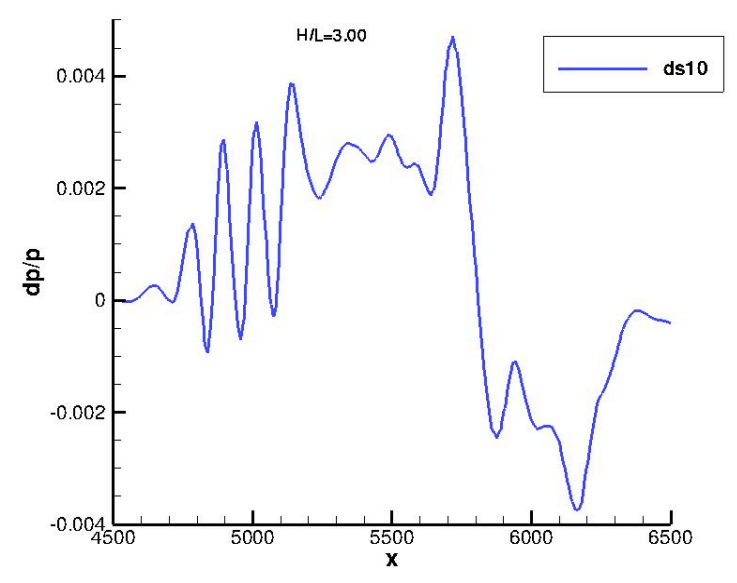

a) $\mathrm{H} / \mathrm{L}=3.00$

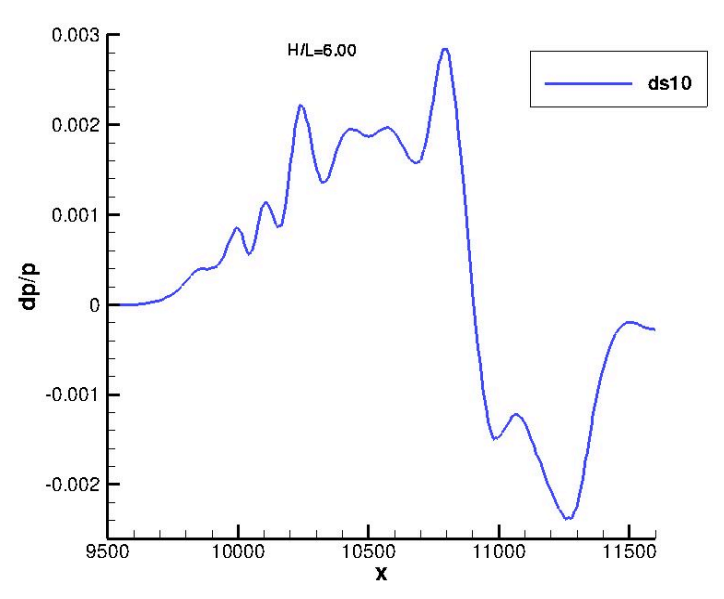

b) $\mathrm{H} / \mathrm{L}=6.00$

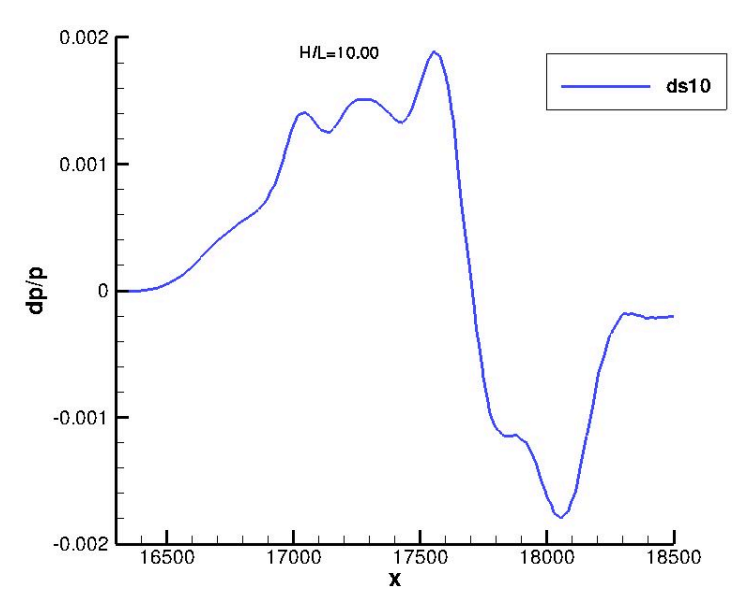

c) $\mathrm{H} / \mathrm{L}=10.00$

Figure 10 - Mid-field signatures for SSGRID high stretching case. 


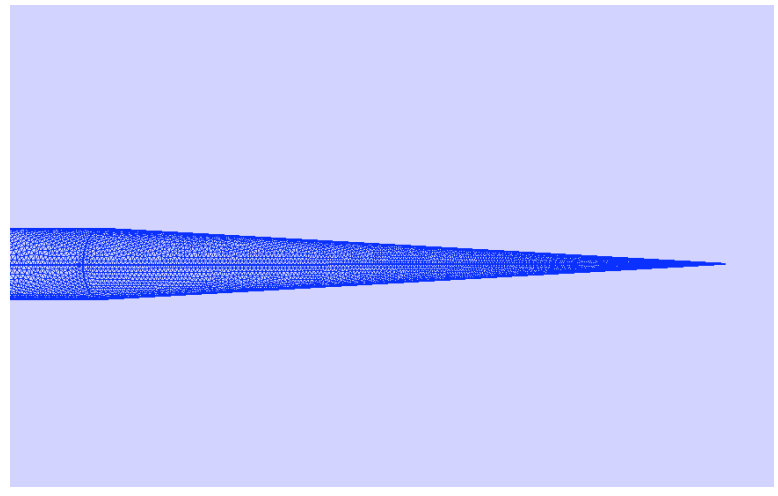

a) Surface grid

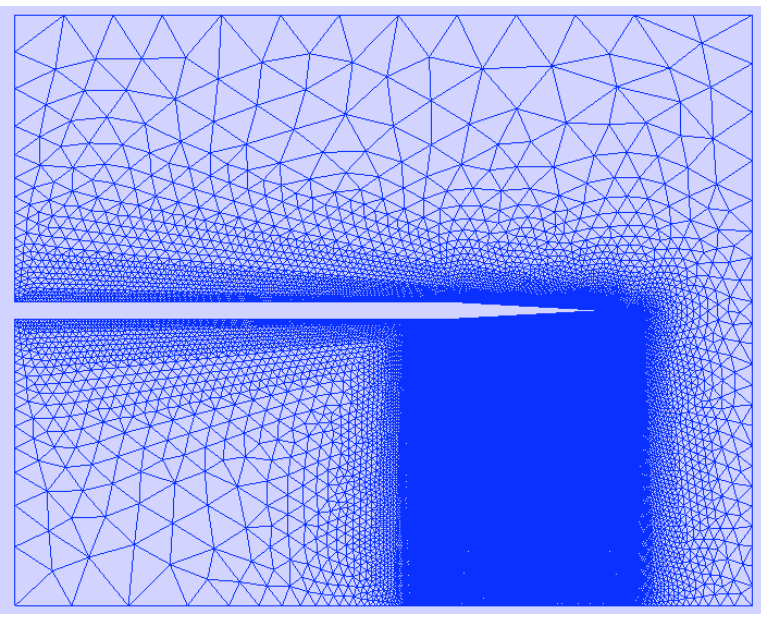

b) symmetry plane grid

Figure 11 - Initial grid for cone model.

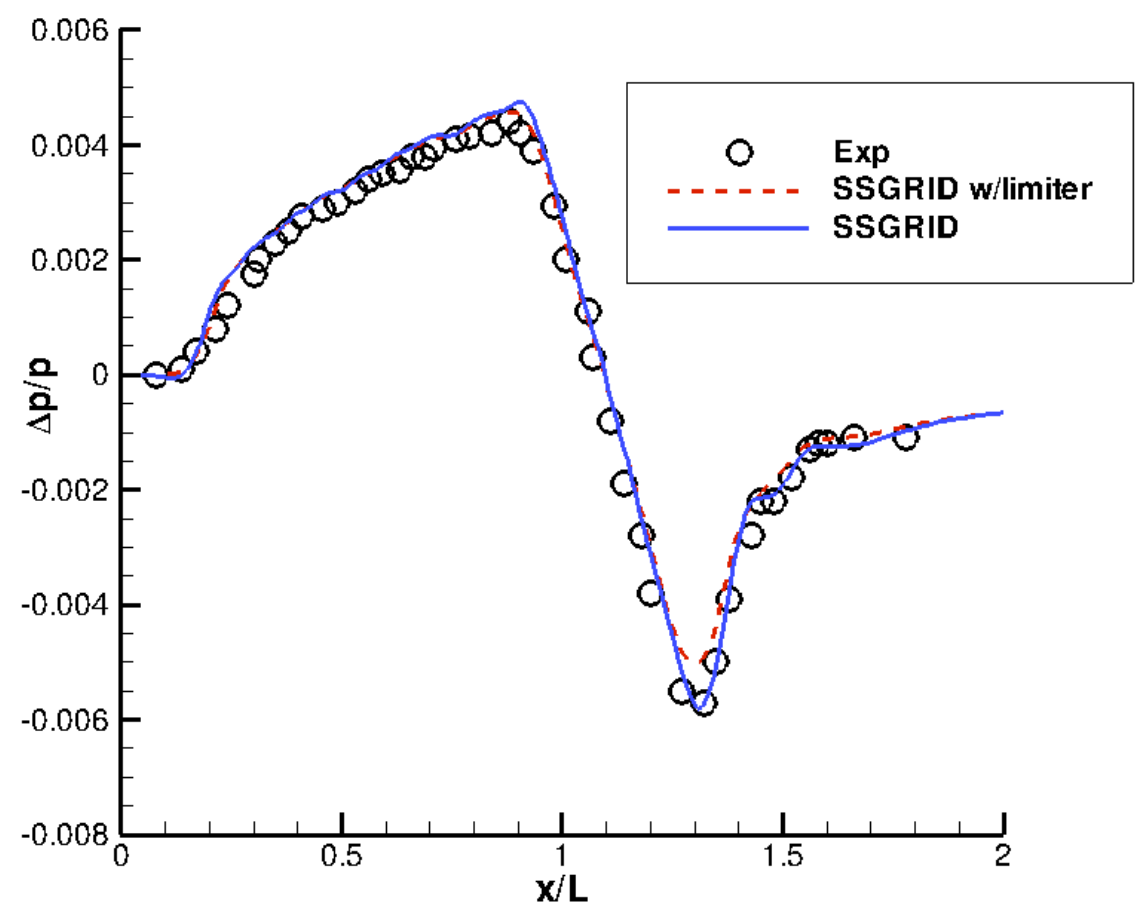

Figure 12 - Mid-field signature $(\mathrm{H} / \mathrm{L}=10)$ for cone model. 


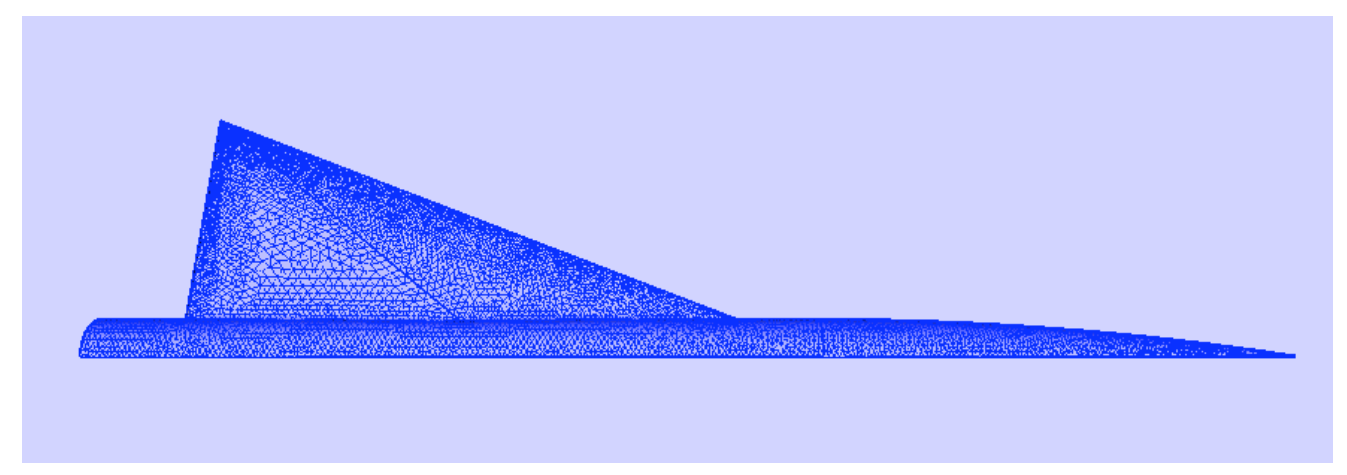

a) Surface grid

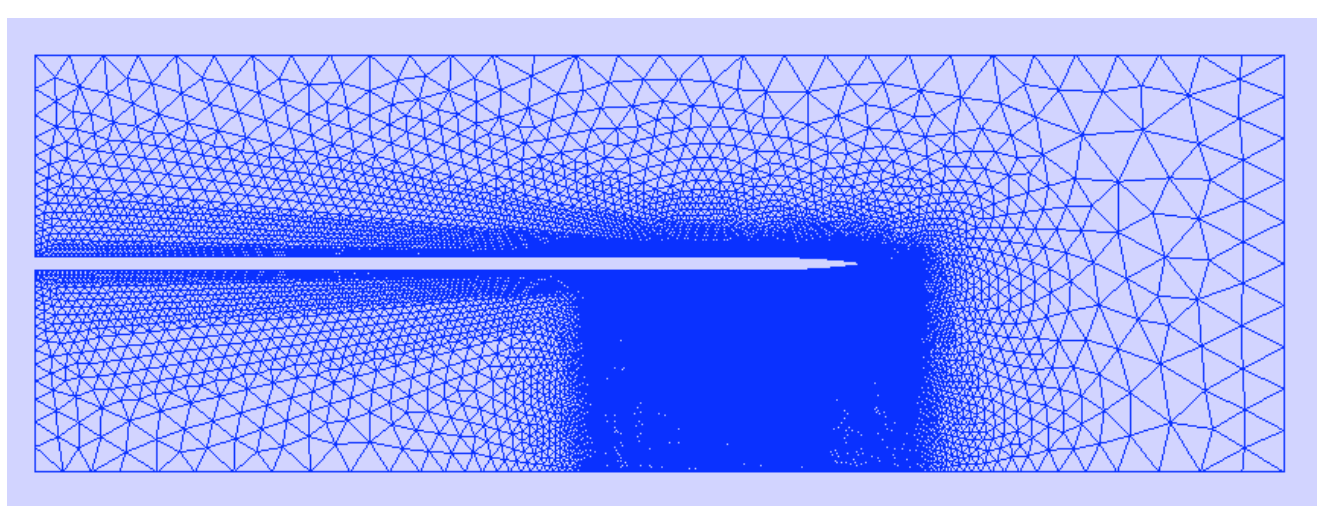

b) Symmetry plane grid

Figure 13 - Initial grid for delta wing configuration.

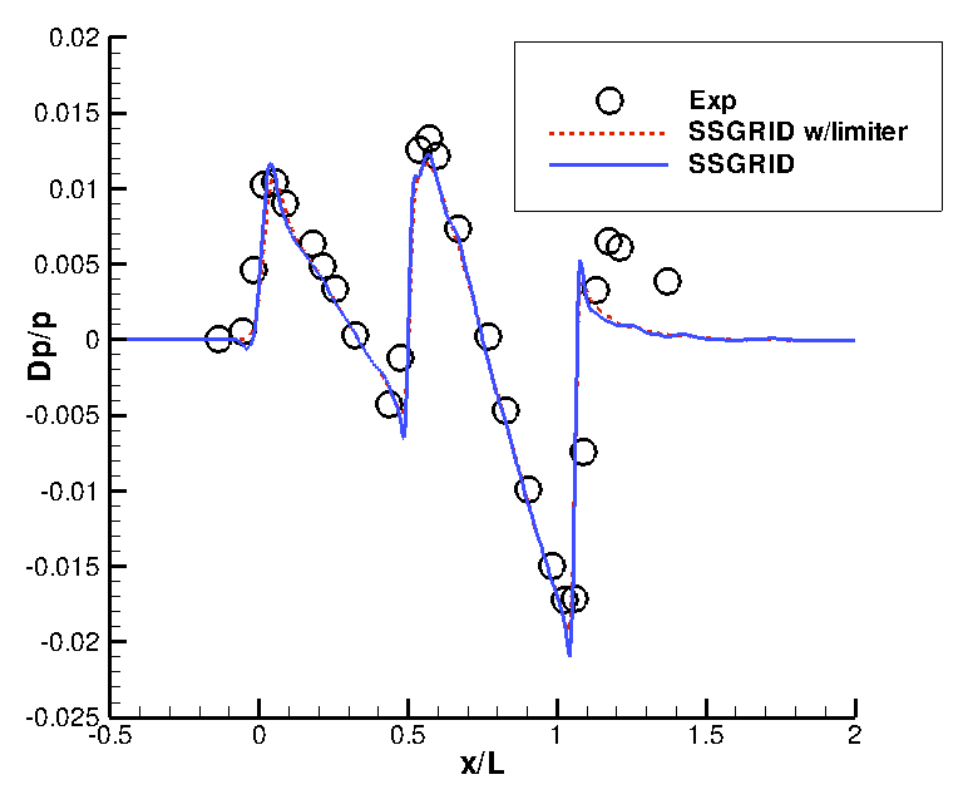

Figure 14 - Mid-field signature (H/L=3.6) for delta wing configuration. 


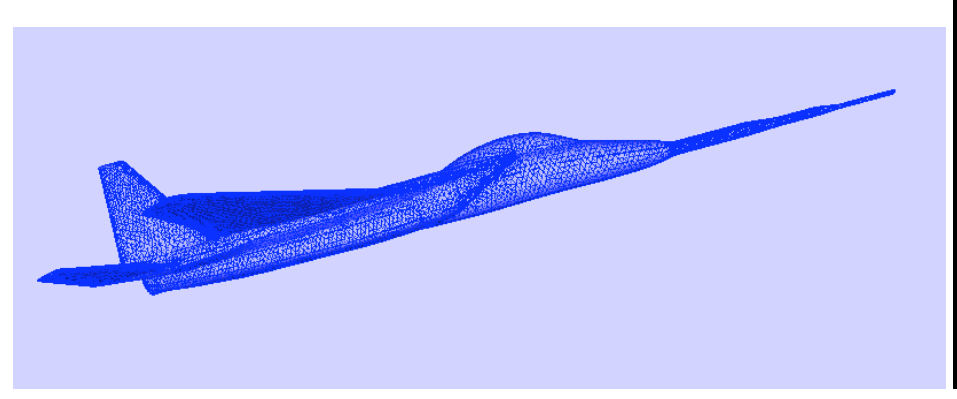

Figure 15 - F-15QS surface grid.

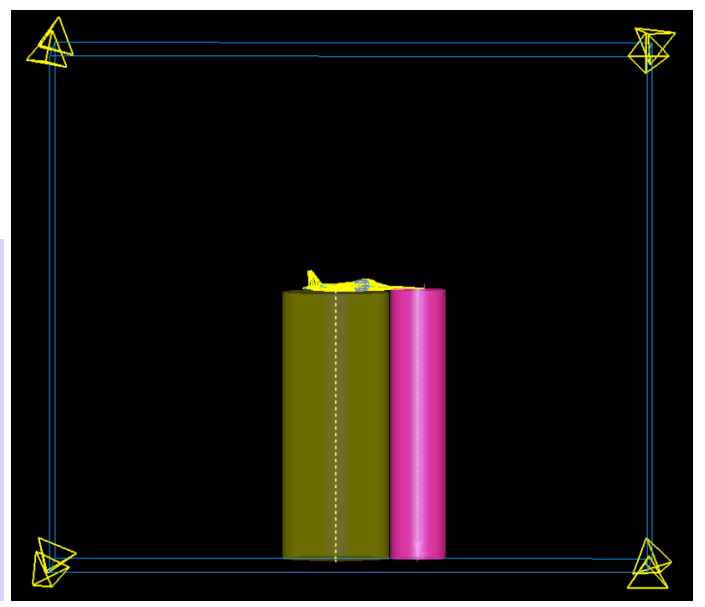

Figure 16 - Location of volume sources.

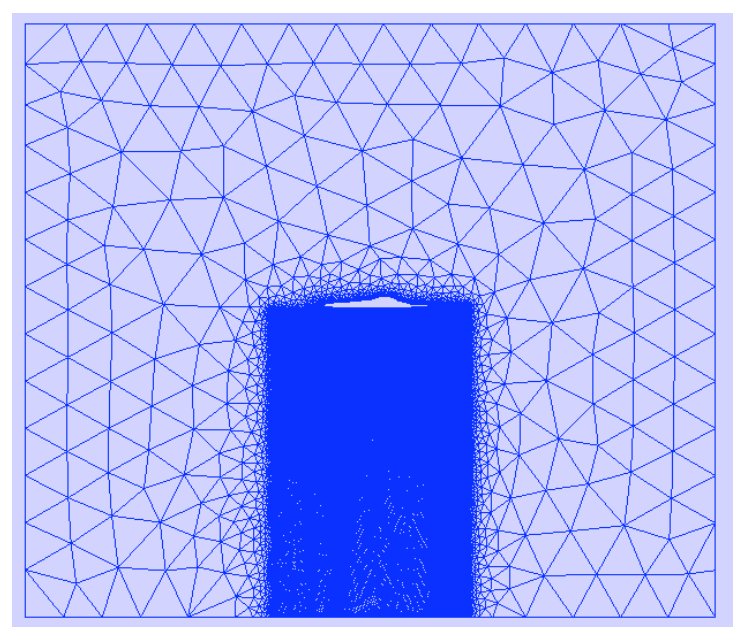

a) Initial grid

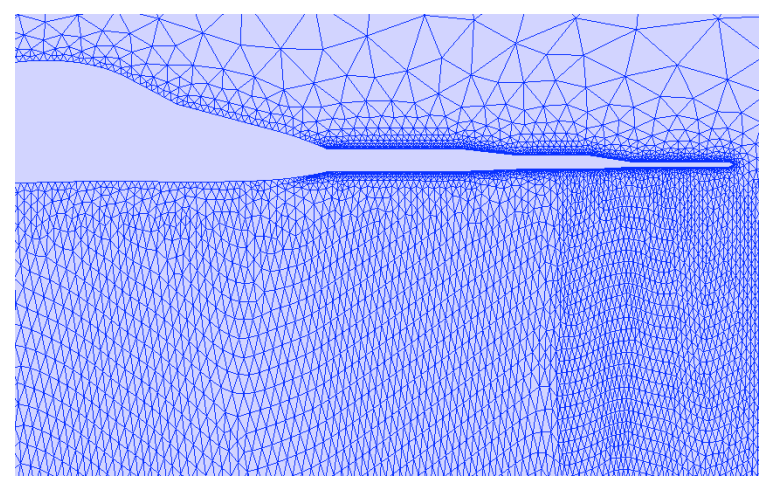

c) Close-up of initial grid

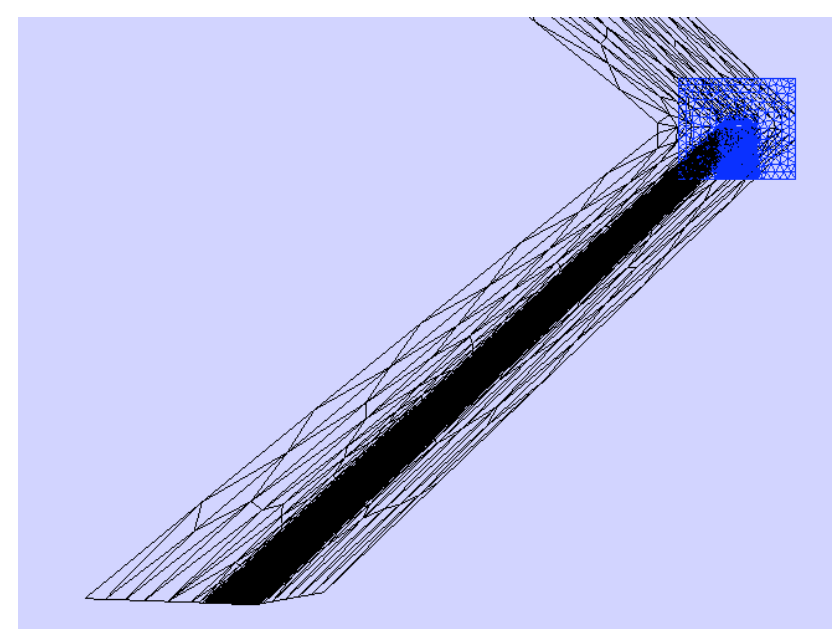

b) SSGRID-high stretching grid

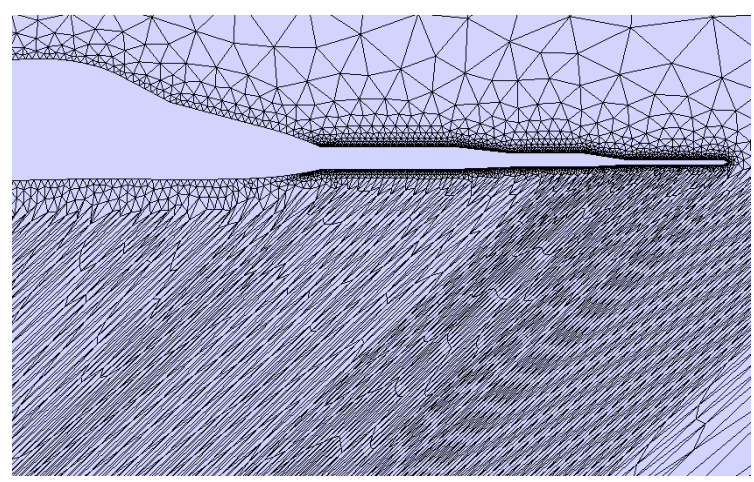

d) Close-up of SSGRID grid

Figure 17 - Symmetry plane grids for F-15QS. 


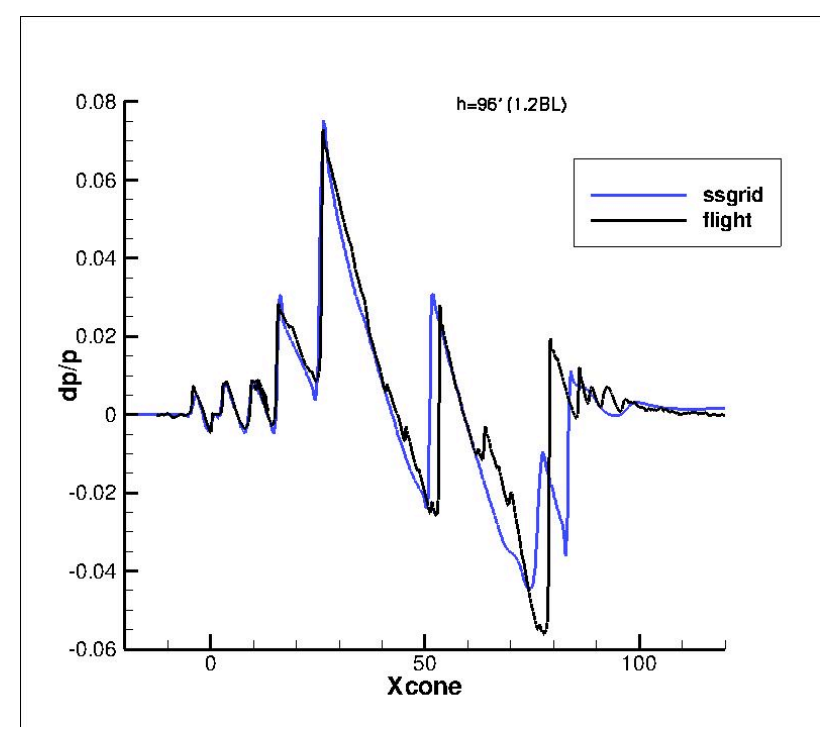

a) $\mathrm{H} / \mathrm{L}=1.2$

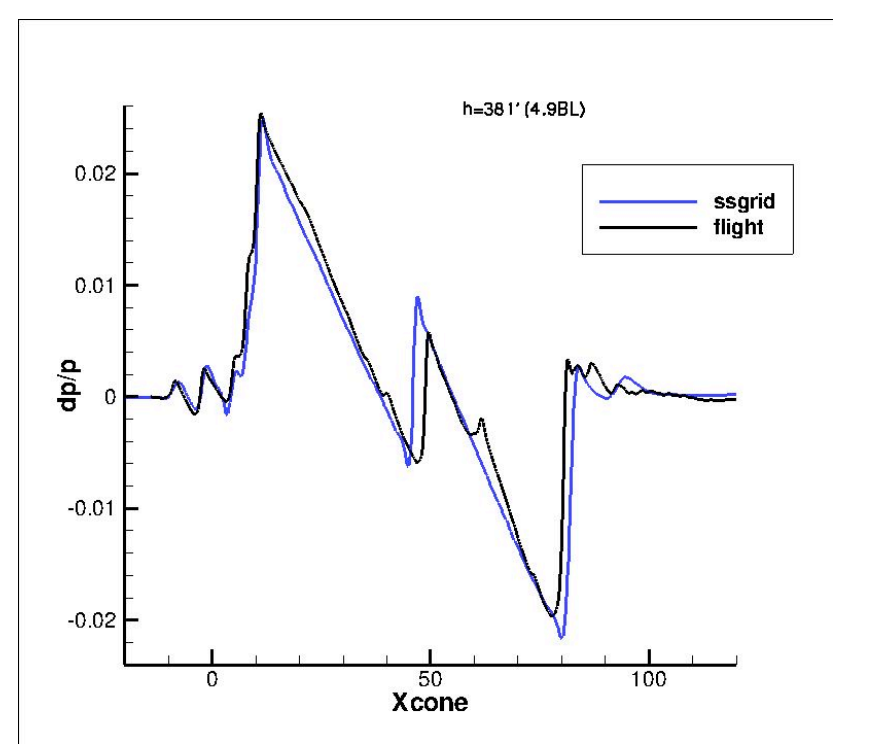

c) $\mathrm{H} / \mathrm{L}=4.8$

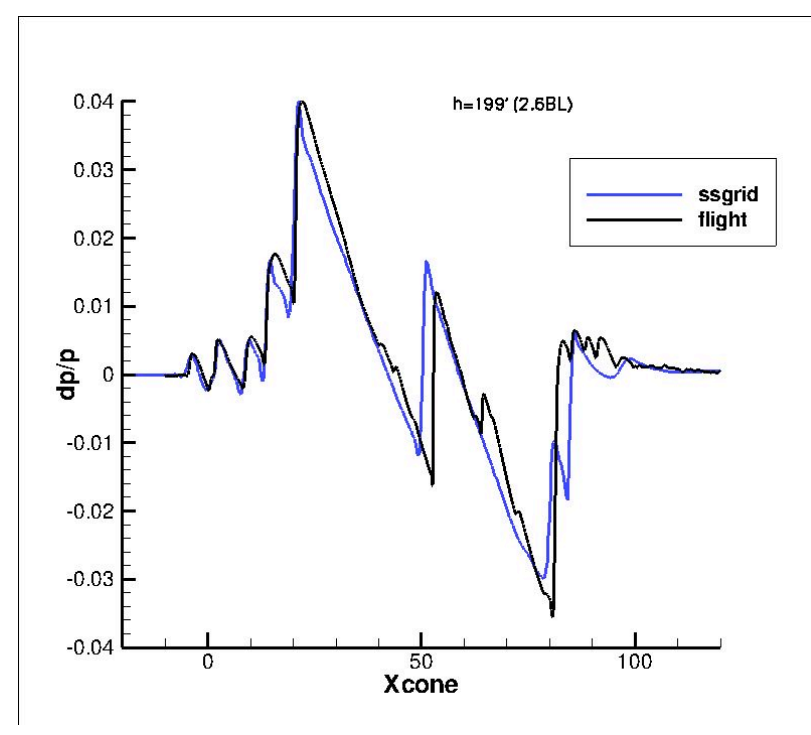

b) $\mathrm{H} / \mathrm{L}=2.6$

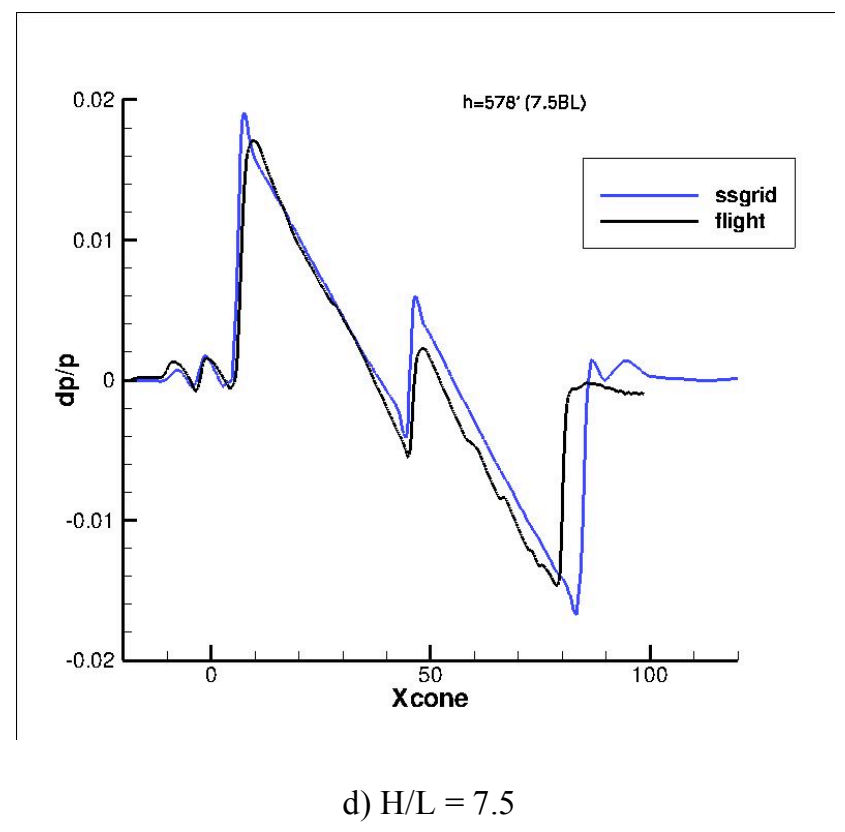

Figure 18 - Comparison of SSGRID results with flight data for F-15QS. 